\title{
Correlation of SOCS-1 gene with onset and prognosis of breast cancer
}

\author{
YUETAO $\mathrm{LV}^{1 *}$, GE SONG ${ }^{2 *}$ and PENG LI ${ }^{1}$ \\ Departments of ${ }^{1}$ Breast and Thyroid Surgery and ${ }^{2}$ Health Management, \\ Jining First People's Hospital, Jining, Shandong 272000, P.R. China
}

Received September 28, 2017; Accepted April 17, 2018

DOI: $10.3892 / \mathrm{ol} .2018 .8675$

\begin{abstract}
The aim of the present study is to study the expressions of suppressor of cytokine signaling (SOCS)-1 in the tumor tissues and adjacent normal tissues of patients with breast cancer. The study was also planned to investigate the association of SOCS-1 gene expression with patients' clinical pathology, molecular subtype and prognosis. A total of 60 cases of frozen and paraffin-embedded specimens of tumor tissues and corresponding adjacent normal tissues of patients with breast cancer were selected. Reverse transcription-quantitative polymerase chain reaction (RT-qPCR) was used to detect the expression levels of SOCS-1 messenger RNA (mRNA) in the patients' tumor tissues and adjacent normal tissues. The immunohistochemical method was applied to detect the expressions of SOCS-1 proteins in the patients' breast cancer tissues and adjacent normal tissues. Moreover, the correlations of SOCS-1 protein expressions in breast cancer tissues with patients' pathological parameters, molecular subtypes and prognosis were analyzed in combination with the clinical data. The results of RT-qPCR showed that the SOCS-1 mRNA expression in breast cancer tissues was significantly lower than that in adjacent normal tissues $(p<0.01)$. The immunohistochemical results indicated that the positive expression rate of the SOCS-1 proteins in breast cancer tissues $(23.33 \%)$ was remarkably lower than that in adjacent normal tissues $(88.33 \%)(\mathrm{p}<0.01)$. The low expression of SOCS-1 in breast cancer tissues was related to lymph node metastasis and clinical staging. The positive expression rates of the luminal A SOCS-1 proteins were the highest $(47.62 \%)(\mathrm{p}<0.01)$. The 5 -year overall survival rate of the breast cancer patients was $63.33 \%$ (38/60). The univariate survival analysis revealed
\end{abstract}

Correspondence to: Dr Peng Li, Department of Breast and Thyroid Surgery, Jining First People's Hospital, 6 Jiankang Road, Jining, Shandong 272000, P.R. China

E-mail: zglw663@163.com

*Contributed equally

Key words: breast cancer, suppressor of cytokine signaling-1, pathological parameters, prognosis that the patients with low expression of SOCS-1 had poorer prognosis. In conclusion, the low expression of SOCS-1 plays a key role in the pathogenesis of breast cancer; in particular, it is associated with the lymph node metastasis and clinical staging of the tumor; so, the SOCS-1 expression in breast cancer tissues can be regarded as an important reference for the prognostic estimation of breast cancer.

\section{Introduction}

Breast cancer is one of the common malignant tumors that occur among women, with a very high incidence rate (1). In addition, breast cancer has a high metastasis rate, which is mainly instigated by lymphatic vessels and reflux veins of the female breasts. Further, lung, liver and brain metastases are often reported in breast cancer patients at an early stage. Therefore, the clinical treatment effects of the patients are quite poor, and the death rates are significantly high (2). Currently, the clinical treatment of breast cancer mainly includes surgical resection, radiotherapy and chemotherapy. Although a certain effect has been achieved, the relapse and metastasis rates of the breast cancer in patients are still fairly high, leading to universally poor prognosis of the patients (3-5).

Suppressor of cytokine signaling (SOCS) is a newly discovered category of immunosuppressive molecules. Furthermore SOCS-1 is a type of suppressor gene that has been widely studied. It has been confirmed for its regulatory role in multiple cytokine signal transduction pathways (6). SOCS-1 gene is located on the chromosome 16p13.3 and could encode proteins containing 211 amino acids (7). SOCS-1 could adjust the Janus kinase/signal transducer and activator of transcription (JAK/STAT) signaling pathway as it has the ability to interact with JAK kinases, induce inactivation of JAK tyrosine kinases and further inhibit the activation of STAT (8). When the SOCS-1 expression is lowered, it could activate the JAK/STAT pathway, causing proliferation, metastasis and invasion of tumor tissues (9).

Current studies have found that SOCS-1 protein is expressed slowly in cervical, prostate, liver, esophageal and pancreatic cancer (10-13). However, there is no literature reporting the expression of SOCS-1 in tissues of breast cancer patients. As a result, the present study aimed to investigate the expression of SOCS-1 in the tumor tissues of patients with breast cancer. Also, its effects on the pathological parameters, molecular 
subtypes and prognosis of breast cancer were evaluated. In this experiment, the reverse transcription-quantitative polymerase chain reaction (RT-qPCR) and immunohistochemical methods were utilized to study the SOCS-1 expressions in tumor tissues and adjacent normal tissues of the patients with breast cancer. Further, the effects of SOCS-1 expressions on the pathological parameters, molecular subtypes and prognosis of the patients with breast cancer were analyzed in combination with the clinical data.

\section{Materials and methods}

Materials. In the present study, 60 women patients with breast cancer who were admitted to Jining First People's Hospital (Jining, China) from September, 2010 to September, 2011 were selected as study subjects. Subjects aged 22-77 years old, with a median age of 53 years old. All the patients were clinically and pathologically diagnosed with breast cancer and were given surgical treatments for the first time without chemotherapy and radiotherapy. The tumor tissues and cancer-adjacent normal tissues were located $10 \mathrm{~cm}$ away from each other and were excised during the surgery. A part of the tissues were stored in liquid nitrogen immediately, and the remaining was fixed in $10 \%$ paraformaldehyde solution. This was followed by formation of paraffin sections. All the patients had complete follow-up records, including age, tumor size, lymph node status, clinical staging and survival conditions. The present study was reviewed and approved by the Medical Ethics Committee of Jining First People's Hospital, and all the patients or their families had signed the informed consent.

TRIzol RNA extraction kit, reverse transcription kit and RT-qPCR kit (Invitrogen; Thermo Fisher Scientific, Inc., Carlsbad, CA, USA); primer synthesis (Takara Biotechnology Co., Ltd., Dalian, China); SOCS-1 antibodies, glyceraldehyde-3-phosphate dehydrogenase (GAPDH) antibodies and horseradish peroxidase (HRP)-labeled secondary antibodies (BD Pharmingen, San Diego, CA, USA); immunohistochemical staining kit SP-9001 (Beijing Zhongshan Golden Bridge Biotechnology Co., Ltd.; OriGene Technologies, Beijing, China).

Detection of SOCS-1 messenger RNA ( $m R N A)$ expressions in patients' tissue specimens via RT-qPCR method. The TRIzol method was used to extract the total RNA in the patients' frozen tissues. Further, the concentration and purity of the extracted RNA were measured via ultraviolet spectrophotometric assay. The samples with an A260/A280 ratio of 1.8-2.0 were selected for subsequent operations. One milligram total RNA of every patient was measured and taken for reverse transcription in accordance with the procedures as prescribed in the kit instructions. This was followed by addition of SOCS-1 primers, and qPCR method was applied to detect the expression of SOCS-1 mRNA. In this experiment, GAPDH was selected as the internal control. The primer sequences are shown in Table I. Specific reaction conditions: $94^{\circ} \mathrm{C}$ for $5 \mathrm{~min}$, denaturation at $94^{\circ} \mathrm{C}$ for $30 \mathrm{sec}$, annealing at $60^{\circ} \mathrm{C}$ for $30 \mathrm{sec}$, extension at $72^{\circ} \mathrm{C}$ for $30 \mathrm{sec}$ and amplification for 35 cycles. The experimental results were analyzed using $2^{-\Delta \Delta \mathrm{Cq}}$ method, of which $\Delta \mathrm{Cq}$ (target gene) $=\mathrm{Cq}$ (target gene) - $\mathrm{Cq}$ (reference gene).
Table I. RT-qPCR primer sequences.

\begin{tabular}{lcc} 
Gene & \multicolumn{2}{c}{ Primer sequence } \\
\hline SOCS-1 & F & 5'-CACGCACTTCCGCACATrCC-3' \\
& R & 5'-TCCAGCAGCTCGAAGAGGCA-3' \\
GAPDH & F & 5'-GCACCGTCAAGGCTGAGAAC-3' \\
& R & 5'-TGGTGAAGACGCCAGTGGA-3'
\end{tabular}

RT-qPCR, reverse transcription-quantitative polymerase chain reaction; SOCS, suppressor of cytokine signaling; F, forward; R, reverse.

Detection of SOCS-1 protein expressions in patients' tissues via immunohistochemical method. The streptavidin-peroxidase (SP) two-step method was utilized to perform immunohistochemical staining. Major steps: after deparaffinization via conventional methods, $3 \% \mathrm{H}_{2} \mathrm{O}_{2}$ was used to block the endogenous peroxidase, citric acid solution was utilized for hotfix, and goat serum for blocking. SOCS-1 primary antibodies (diluted at 1:200; cat. no. 554002; BD Pharmingen, San Diego, CA, USA) were added in drips and then kept at $4{ }^{\circ} \mathrm{C}$ overnight. The secondary polyclonal antibodies (diluted at 1 : 1,000) were then added and incubated at room temperature for $1 \mathrm{~h}$. All the above-mentioned steps underwent washing with phosphate-buffered saline (PBS) for 3 min 3 times. Finally, the diaminobenzidine (DAB) was added in drips for development and hematoxylin for counterstaining. PBS as the negative control replaced the primary antibodies.

The double-blind method was applied to analyze the results observed by a microscope (Olympus, Tokyo, Japan). The judgment of positive expression was based on the comprehensive judgment of the percentage of positive cells and staining intensity. Percentage of positive cells: $<5 \%, 0$ point; $6-25 \%, 1$ point; 26-50\%, 2 points; and >50\%, 3 points; staining intensity: not stained, 0 point; light yellow, 1 point; yellowish-brown, 2 points; and sepia, 3 points. Six high-power fields were selected randomly. Further, the two kinds of scores were added together: $\leq 3$ points, negative; and $>3$ points, positive.

Correlation of SOCS-1 expressions in breast cancer patients tumor tissues with patients' pathological parameters and prognosis. A total of 60 patients with breast cancer were divided into positive and negative SOCS-1 expression groups according to the expression levels of SOCS-1 in breast cancer tissues. The clinicopathological parameters of the patients were recorded, and the correlation of SOCS-1 expressions with patients' pathological parameters, molecular subtypes and prognosis were analyzed. All the patients underwent modified radical mastectomy. The follow-up time was counted from the first day after the surgery and the survival time was calculated. The overall survival time referred to the duration from the first day after the surgery to the date of death or the last follow-up. The follow-up was conducted once a month for 5 years.

Statistical processing. Statistical Product and Service Solutions (SPSS) 17.0 software (SPSS, Inc., Chicago, IL, USA) was used for data recording and processing. All the measurement data are expressed as mean \pm standard deviation. 


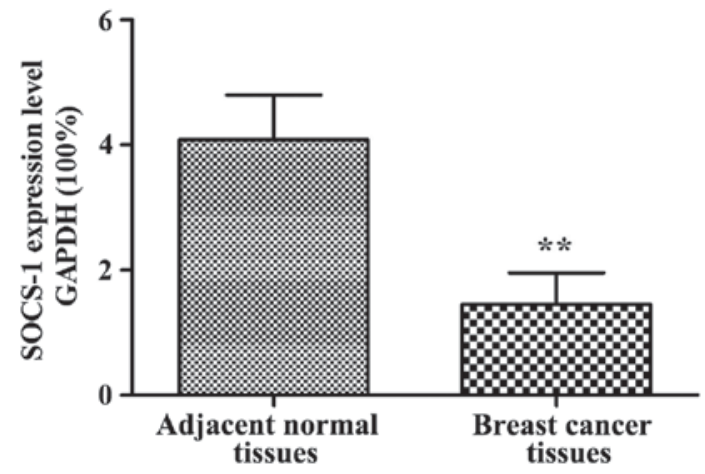

Figure 1. Detection of SOCS-1 mRNA expressions in patients' tissues via RT-qPCR method. The expression of SOCS-1 mRNA in tissues of patients with breast cancer is obviously decreased compared with that in adjacent normal tissues, ${ }^{* *} \mathrm{p}<0.01$. SOCS, suppressor of cytokine signaling; mRNA, messenger RNA; RT-qPCR, reverse transcription-quantitative polymerase chain reaction.
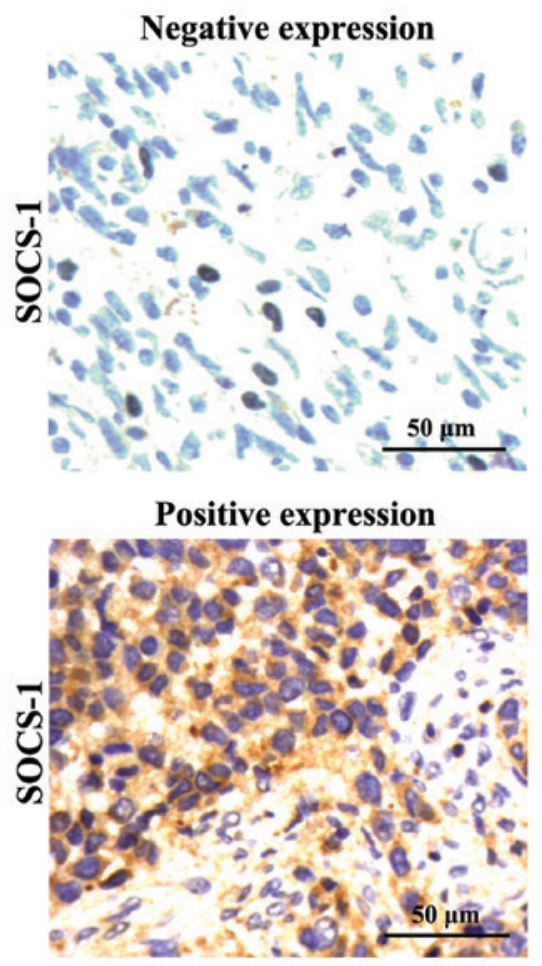

Figure 2. Detection of SOCS-1 protein expressions in patients' tissues via immunohistochemical method. The expression level of SOCS-1 in breast cancer tissues is significantly decreased compared with that in adjacent normal tissues. SOCS, suppressor of cytokine signaling.

Further, t-test was utilized for comparison between two groups; $\chi^{2}$ test was performed for comparison of enumeration data between groups. The Kaplan-Meier method was utilized to conduct univariate survival analysis. $\mathrm{P} \leq 0.05$ suggested that the difference was statistically significant.

\section{Results}

Detection of SOCS-1 mRNA expressions in patients' tissues via RT-qPCR method. The results of SOCS-1 mRNA expressions in tumor tissues and adjacent normal tissues of patients with breast cancer are shown in Fig. 1. The relative expression
Table II. Correlation of abnormal SOCS-1 expressions with clinicopathological parameters of breast cancer patients.

\begin{tabular}{lccccc}
\hline & & \multicolumn{5}{c}{ SOCS-1 } \\
\cline { 3 - 6 } Clinical data & $\begin{array}{c}\text { Cases } \\
(\mathrm{n})\end{array}$ & $\begin{array}{c}\text { Negative } \\
(\mathrm{n}, \%)\end{array}$ & $\begin{array}{c}\text { Positive } \\
(\mathrm{n}, \%)\end{array}$ & $\begin{array}{c}\chi^{2} \\
\text { value }\end{array}$ & P-value \\
\hline Age (years) & & & & & \\
$\leq 40$ & 32 & $26(81.25)$ & $6(18.75)$ & 0.81 & 0.12 \\
$>40$ & 28 & $20(71.43)$ & $8(28.58)$ & & \\
Tumor size (cm) & & & & & \\
$\leq 5$ & 29 & $21(72.41)$ & $8(27.59)$ & 0.57 & 0.11 \\
$>5$ & 31 & $25(80.65)$ & $6(19.35)$ & & \\
Lymphatic & & & & & \\
metastasis & & & & & \\
$\quad$ No & 24 & $15(62.50)$ & $9(37.50)$ & 4.49 & 0.03 \\
$\quad$ Yes & 36 & $31(86.11)$ & $5(13.89)$ & & \\
Clinical staging & & & & & \\
I-II & 31 & $20(64.52)$ & $11(35.48)$ & 5.29 & 0.02 \\
III-IV & 29 & $26(89.66)$ & $3(10.34)$ & & \\
\hline
\end{tabular}

SOCS, suppressor of cytokine signaling.

of SOCS-1 mRNA in tumor tissues of patients with breast cancer was significantly decreased as compared to adjacent normal tissues $(\mathrm{p}<0.01)$.

Detection of SOCS-1 protein expressions in patients' tissue specimens via immunohistochemical method. The immunohistochemical results are shown in Fig. 2. The positive SOCS-1 protein was manifested as sepia deposition of cytoplasm. According to the statistical analysis on the staining results, the positive expression rate of SOCS-1 proteins in tumor tissues of patients with breast cancer was $23.33 \%$ (14/60), and in adjacent normal tissues was $88.33 \%$ (53/60), respectively. The differences were statistically significant $(\mathrm{p}<0.01)$.

Correlation of SOCS-1 expressions in breast cancer patients tumor tissues with clinicopathological parameters. The patients with breast cancer were divided into positive and negative SOCS-1 expression group in accordance with the immunohistochemical results. $\chi^{2}$ test was performed to analyze the relationship between the SOCS-1 expressions in the tissues of patients with breast cancer and the patients' clinicopathological parameters. The negative SOCS-1 expression in patients' tumor tissues was associated with the lymph node metastasis and clinical staging of the tumor $(\mathrm{p}<0.05)$ (Table II).

Correlation of SOCS-1 expressions with molecular typing in breast cancer patients' tumor tissues. $\chi^{2}$ test was utilized to analyze the relationship between the SOCS-1 expressions and molecular typing in the tissues of patients with breast cancer; as shown in Table III. The positive expression rate of luminal A SOCS-1 proteins was the highest (47.62\%), and the SOCS-1 expressions in different molecular subtypes varied remarkably $(\mathrm{p}<0.01)$. 
Table III. Correlation of abnormal SOCS-1 expressions with molecular typing of breast cancer.

\begin{tabular}{lrcccc}
\hline & & \multicolumn{4}{c}{ SOCS-1 } \\
\cline { 3 - 6 } $\begin{array}{l}\text { Molecular } \\
\text { subtype }\end{array}$ & $\begin{array}{c}\text { Cases } \\
(\mathrm{n})\end{array}$ & $\begin{array}{c}\text { Negative } \\
(\mathrm{n}, \%)\end{array}$ & $\begin{array}{c}\text { Positive } \\
(\mathrm{n}, \%)\end{array}$ & $\begin{array}{c}\chi^{2} \\
\text { value }\end{array}$ & P-value \\
\hline $\begin{array}{l}\text { Luminal A } \\
\text { Luminal B }\end{array}$ & 21 & $11(52.38)$ & $10(47.62)$ & 11.62 & 0.067 \\
$\begin{array}{l}\text { HER-2 } \\
\text { overexpression }\end{array}$ & 18 & $17(94.44)$ & $1(5.56)$ & & \\
Basal-like & 9 & $11(91.67)$ & $1(8.33)$ & & \\
\hline
\end{tabular}

SOCS, suppressor of cytokine signaling; HER-2, human epidermal growth factor receptor-2.

Table IV. Univariate analysis on correlation of SOCS-1 expressions with overall survival rate of breast cancer patients.

\begin{tabular}{lccccc}
\hline $\begin{array}{l}\text { SOCS-1 } \\
\text { group }\end{array}$ & $\begin{array}{c}\text { Cases } \\
\text { (n) }\end{array}$ & $\begin{array}{c}\text { Cases } \\
\text { survived in } \\
5 \text { years (n) }\end{array}$ & $\begin{array}{c}\text { 5-year } \\
\text { survival } \\
\text { rate (\%) }\end{array}$ & $\begin{array}{c}\text { Wald } \\
\text { (log-rank) }\end{array}$ & P-value \\
\hline $\begin{array}{l}\text { Positive } \\
\text { expression }\end{array}$ & 14 & 12 & 85.71 & 4.15 & $<0.05$ \\
$\begin{array}{l}\text { Negative } \\
\text { expression }\end{array}$ & 46 & 26 & 56.52 & & \\
\hline
\end{tabular}

SOCS, suppressor of cytokine signaling.

Analyses on patients' survival conditions and prognosis. After 5 years of follow-up, among the 60 patients with breast cancer, 38 survived and 22 were dead. The 5 -year overall survival rate of the patients was $63.33 \%$ (38/60). The Kaplan-Meier survival analysis results are shown in Fig. 3. The prognosis of patients with negative SOCS-1 expression was poor. The univariate survival analysis results are shown in Table IV. SOCS-1 could influence the overall survival rate of the patients with breast cancer $(\mathrm{p}<0.05)$.

\section{Discussion}

Recently, literature has shown significant rise in the incidence of younger breast cancer patients. Moreover, its death rate is also rising year by year. The onset of breast cancer is related to variations in transcriptions and expressions of many genes, and the clinical treatment effects fail to live up to people's expectations. Therefore, breast cancer has posed a serious threat to women's life and health (14-16). So far, the individualized treatment of breast cancer is an emerging treatment protocol that requires analysis of the gene expressions of the breast cancer patients. This divides the patients into different subtypes, which allow application of different therapeutic methods and drugs according to the subtypes (17).

The N-terminal of SOCS-1 protein is the inhibition section of kinase, in which a tyrosine residue is used as the

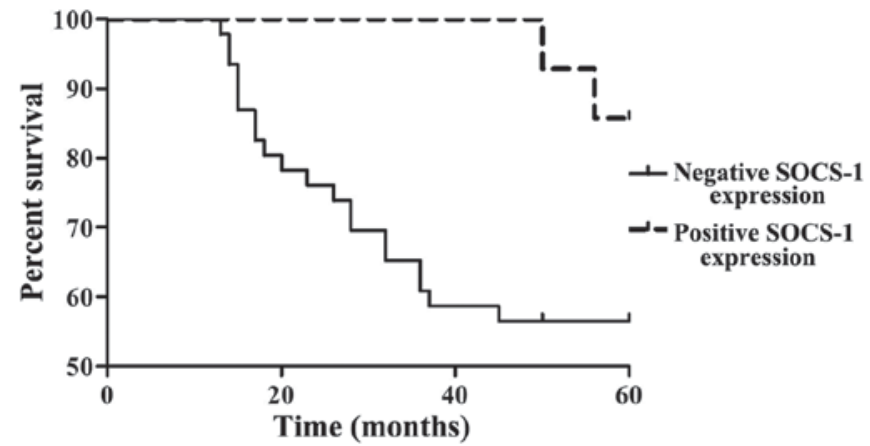

Figure 3. SOCS-1 expressions and Kaplan-Meier survival curves of patients with breast cancer. Compared with patients with positive SOCS-1 expression, the patients with negative SOCS-1 expression have poorer prognosis. SOCS, suppressor of cytokine signaling.

pseudosubstrate of JAK-2. Further, it could compete with STAT for the binding sites in the JAK catalytic zone, thereby negatively regulating the JAK/STAT signaling pathway (18). The JAK/STAT signaling pathway plays key roles in the occurrence, proliferation, metastasis and invasion processes of tumor tissues (19). Some studies have found that SOCS-1 protein was slowly expressed in the tumor tissues of patients with prostate cancer. Furtehr, the low SOCS-1 expression could lead to upregulation of the expressions of cyclins and cyclin-dependent kinases, thereby, enhancing the proliferative capacity of prostate cancer cells (12). Moreover, the downregulated SOCS-1 expressions have also been discovered in multiple tumors, including hepatocellular carcinoma, pancreatic cancer, multiple myeloma and acute myeloid leukaemia. The proliferation activity of the tumor tissues was suppressed when the SOCS-1 was highly expressed in them. As a result, SOCS-1 is a suppressor gene (20-22).

The RT-qPCR method was used to detect the expressions of SOCS-1 mRNA in the tumor tissues and adjacent normal tissues of patients with breast cancer in order to investigate the expression of SOCS-1 in the tumor tissues of patients. The results showed that the SOCS-1 mRNA expression level in breast cancer tissues was significantly lower than that of adjacent normal tissues. The immunohistochemical results indicated that the expression of the SOCS-1 proteins in breast cancer tumor tissues was remarkably lower than that of adjacent normal tissues. $\chi^{2}$ test was performed to analyze the relationship between the SOCS-1 protein expressions and the patients' pathological parameters along with molecular subtypes. The results revealed that the negative expression of SOCS-1 protein in patients' tumor tissues was associated with the lymph node metastasis and clinical staging of the tumor. In addition, the SOCS-1 expressions in different molecular subtypes varied remarkably. Furthermore, univariate Kaplan-Meier survival analysis was applied to study the impact of SOCS-1 expressions on the 5-year overall survival rate of the patients. It was observed that the SOCS-1 had a significant influence on the overall survival time of breast cancer patients. The patients with lower expression of SOCS-1 had a lower 5-year survival rate and poorer prognosis. The 5-year overall survival rate of the patients was $63.33 \%$, and the Kaplan-Meier survival analysis results showed that the prognosis of patients with negative SOCS-1 expression was poor. So, SOCS-1 could be regarded 
as an independent factor influencing the overall survival rate of the breast cancer patients.

In conclusion, SOCS-1 has low expression in the tumor tissues of patients with breast cancer, and plays a crucial role in the pathogenesis of breast cancer. Therefore, the SOCS-1 expression in patients' tumor tissues could be regarded as a reference for the prognostic estimation of breast cancer patients.

\section{Acknowledgements}

Not applicable.

\section{Funding}

No funding was received.

\section{Availability of data and materials}

The datasets used and/or analyzed during the current study are available from the corresponding author on reasonable request.

\section{Authors' contributions}

YL extracted RNA. GS performed RT-qPCR. PL helped with immunohistochemical method. All authors read and approved the final manuscript.

\section{Ethics approval and consent to participate}

The present study was reviewed and approved by the Medical Ethics Committee of Jining First People's Hospital (Jining, China), and all the patients or their families had signed the informed consent.

\section{Consent for publication}

Not applicable.

\section{Competing interests}

The authors declare that they have no competing interests.

\section{References}

1. Jemal A, Bray F, Center MM, Ferlay J, Ward E and Forman D: Global cancer statistics. CA Cancer J Clin 61: 69-90, 2011.

2. Garcia-Murillas I, Schiavon G, Weigelt B, Ng C, Hrebien S, Cutts RJ, Cheang M, Osin P, Nerurkar A, Kozarewa I, et al: Mutation tracking in circulating tumor DNA predicts relapse in early breast cancer. Sci Transl Med 7: 302ra133, 2015.

3. Im NK, Jang WJ, Jeong CH and Jeong GS: Delphinidin suppresses PMA-induced MMP-9 expression by blocking the NF- $\kappa \mathrm{B}$ activation through MAPK signaling pathways in MCF-7 human breast carcinoma cells. J Med Food 17: 855-861, 2014.

4. Shalaby MA, Nounou HA, Ms A, O A, Azzam N and Saeed HM: Associations between single nucleotide polymorphisms of COX-2 and MMP-2 genes and colorectal cancer susceptibility in the Saudi population. Asian Pac J Cancer Prev 15: 4989-4994, 2014.

5. Zhou R, Xu L, Ye M, Liao M, Du H and Chen H: Formononetin inhibits migration and invasion of MDA-MB-231 and 4T1 breast cancer cells by suppressing MMP-2 and MMP-9 through PI3K/AKT signaling pathways. Horm Metab Res 46: 753-760, 2014.
6. Starr R, Willson TA, Viney EM, Murray LJ,Rayner JR, Jenkins BJ, Gonda TJ, Alexander WS, Metcalf D, Nicola NA, et al: A family of cytokine-inducible inhibitors of signalling. Nature 387: 917-921, 1997.

7. Yoshimura A, Naka T and Kubo M: SOCS proteins, cytokine signalling and immune regulation. Nat Rev Immunol 7: 454-465, 2007.

8. Endo TA, Masuhara M, Yokouchi M, Suzuki R, Sakamoto H, Mitsui K, Matsumoto A, Tanimura S, Ohtsubo M, Misawa H, et al: A new protein containing an $\mathrm{SH} 2$ domain that inhibits JAK kinases. Nature 387: 921-924, 1997.

9. Senft C, Priester M, Polacin M, Schröder K, Seifert V, Kögel D and Weissenberger J: Inhibition of the JAK-2/STAT3 signaling pathway impedes the migratory and invasive potential of human glioblastoma cells. J Neurooncol 101: 393-403, 2011.

10. Miyoshi H, Fujie H, Moriya K, Shintani Y, Tsutsumi T, Makuuchi M, Kimura S and Koike K: Methylation status of suppressor of cytokine signaling-1 gene in hepatocellular carcinoma. J Gastroenterol 39: 563-569, 2004.

11. Hussain S, Singh N, Salam I, Bandil K, Yuvaraj M, Akbar Bhat M, Muzaffar Mir M, Siddiqi MA, Sobti RC, Bharadwaj M, et al: Methylation-mediated gene silencing of suppressor of cytokine signaling-1 (SOCS-1) gene in esophageal squamous cell carcinoma patients of Kashmir valley. J Recept Signal Transduct Res 31: 147-156, 2011 .

12. Neuwirt H, Puhr M, Santer FR, Susani M, Doppler W, Marcias G, Rauch V, Brugger M, Hobisch A, Kenner L, et al: Suppressor of cytokine signaling (SOCS)-1 is expressed in human prostate cancer and exerts growth-inhibitory function through down-regulation of cyclins and cyclin-dependent kinases. Am J Pathol 174: 1921-1930, 2009.

13. Chu PY, Yeh CM, Hsu NC, Chang YS, Chang JG and Yeh KT: Epigenetic alteration of the SOCS1 gene in hepatocellular carcinoma. Swiss Med Wkly 140: w13065, 2010.

14. Huang S, Chen J and Jia Y: Research on the correlation of MMP9 and $\mathrm{p} 53$ expression with the prognosis of triple negative breast cancer. Xiandai Shengwu Yixue Jinzhan 14: 881-884, 2014.

15. Choi JS, Baek HM, Kim S, Kim MJ, Youk JH, Moon HJ, Kim EK and Nam YK: Magnetic resonance metabolic profiling of breast cancer tissue obtained with core needle biopsy for predicting pathologic response to neoadjuvant chemotherapy. PLoS One 8: e83866, 2013

16. Yari K, Rahimi Z, Moradi MT and Rahimi Z: The MMP-2 -735 C allele is a risk factor for susceptibility to breast cancer. Asian Pac J Cancer Prev 15: 6199-6203, 2014.

17. Lamps LW and Folpe AL: The diagnostic value of hepatocyte paraffin antibody 1 in differentiating hepatocellular neoplasms from nonhepatic tumors: A review. Adv Anat Pathol 10: 39-43, 2003.

18. Kershaw NJ, Murphy JM, Liau NP, Varghese LN, Laktyushin A, Whitlock EL, Lucet IS, Nicola NA and Babon JJ: SOCS3 binds specific receptor-JAK complexes to control cytokine signaling by direct kinase inhibition. Nat Struct Mol Biol 20: 469-476, 2013.

19. Weissenberger J, Priester M, Bernreuther C, Rakel S, Glatzel M, Seifert $\mathrm{V}$ and KögelD: Dietary curcumin attenuates glioma growth in a syngeneic mouse model by inhibition of the JAK1,2/STAT3 signaling pathway. Clin Cancer Res 16: 5781-5795, 2010.

20. Liu TC, Lin SF, Chang JG, Yang MY, Hung SY and Chang CS: Epigenetic alteration of the SOCS1 gene in chronic myeloid leukaemia. Br J Haematol 123: 654-661, 2003.

21. Stanganelli C, Arbelbide J, Fantl DB, Corrado C and Slavutsky I: DNA methylation analysis of tumor suppressor genes in monoclonal gammopathy of undetermined significance. Ann Hematol 89: 191-199, 2010.

22. Watanabe D, Ezoe S, Fujimoto M, Kimura A, Saito Y, Nagai H, Tachibana I, Matsumura I, Tanaka T, Kanegane H, et al: Suppressor of cytokine signalling-1 gene silencing in acute myeloid leukaemia and human haematopoietic cell lines. Br J Haematol 126: 726-735, 2004.

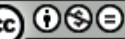

This work is licensed under a Creative Commons Attribution-NonCommercial-NoDerivatives 4.0 International (CC BY-NC-ND 4.0) License. 